E. M. Bingham - J. T. Dunn · D. Smith - J. Sutcliffe-Goulden - L. J. Reed •

P. K. Marsden - S. A. Amiel

\title{
Differential changes in brain glucose metabolism during hypoglycaemia accompany loss of hypoglycaemia awareness in men with type 1 diabetes mellitus. An $\left[{ }^{11} \mathrm{C}\right]-3-0$-methyl-D-glucose PET study
}

Received: 17 February 2005 / Accepted: 11 May 2005 / Published online: 6 September 2005

(C) Springer-Verlag 2005

\begin{abstract}
Aims/hypothesis: Hypoglycaemia unawareness in type 1 diabetes increases the risk of severe hypoglycaemia and impairs quality of life for people with diabetes. To explore the central mechanisms of hypoglycaemia awareness, we used $\left[{ }^{11} \mathrm{C}\right]-3-O$-methyl-D-glucose $(\mathrm{CMG})$ positron emission tomography (PET) to measure changes in global and regional brain glucose metabolism between euglycaemia and hypoglycaemia in aware and unaware diabetic subjects. Materials and methods: Twelve men with type 1 diabetes, of whom six were characterised as aware and six as unaware of hypoglycaemia, underwent two CMG-PET brain scans while plasma glucose was
\end{abstract}

E. M. Bingham · J. T. Dunn · D. Smith $\cdot$ S. A. Amiel Department of Diabetes, Endocrinology and Internal Medicine, Guy's, King's and St Thomas' School of Medicine, King's College,

London, UK

J. T. Dunn · J. Sutcliffe-Goulden $\cdot$ P. K. Marsden The PET Imaging Centre,

Guy's, King's and St. Thomas' School of Medicine,

King's College,

London, UK

L. J. Reed

Department of Psychological Medicine,

Institute of Psychiatry, King's College,

London, UK

Present address:

J. Sutcliffe-Goulden

Department of Biomedical Engineering,

University of California,

Davis, CA, USA

S. A. Amiel $(\bowtie)$

Medical School Building,

Guy's, King's and St Thomas' School of Medicine,

King's College,

Denmark Hill Campus, Bessemer Road,

London, SE5 9PJ, UK

e-mail: stephanie.amiel@kcl.ac.uk

Tel.: +44-207-3464161

Fax: +44-207-3463685 controlled by insulin and glucose infusion either at euglycaemia $(5 \mathrm{mmol} / \mathrm{l})$ or at hypoglycaemia $(2.6 \mathrm{mmol} / \mathrm{l})$ in random order. Results: With hypoglycaemia, symptoms and sweating occurred only in the aware group. Brain glucose content fell in both groups $(p=0.0002$; aware, $1.18 \pm$ 0.45 to $0.02 \pm 0.2 \mathrm{mmol} / \mathrm{l}$; unaware, $1.07 \pm 0.46$ to $0.19 \pm 0.23$ $\mathrm{mmol} / \mathrm{l}$ ), with a relative increase in tracer uptake in prefrontal cortical regions, including the anterior cingulate. No detectable differences were found between groups in global brain glucose transport parameters $\left(K_{1}, k_{2}\right)$. The cerebral metabolic rate for glucose (CMRglc) showed a relative rise in the aware subjects $(11.839 \pm 2.432$ to $13.958 \pm$ 2.372 ) and a fall in the unaware subjects (from 12.457 1.938 to $\left.10.16 \pm 0.801 \mu \mathrm{mol} 100 \mathrm{~g}^{-1} \min ^{-1}, p=0.043\right)$. Conclusions/interpretation: Hypoglycaemia is associated with reduced brain glucose content in aware and unaware subjects, with a relative preservation of metabolism in areas associated with sympathetic activation. The relative rise in global glucose metabolic rate seen in aware subjects during hypoglycaemia contrasted with the relative fall in the unaware subjects and suggests that cortical neuronal activation is a necessary correlate of the state of hypoglycaemia awareness.

Keywords Brain glucose metabolism - Hypoglycaemia unawareness - Positron emission tomography

Abbreviations $\mathrm{CMG}:\left[{ }^{11} \mathrm{C}\right]-3-O$-methyl-D-glucose CMRglc: cerebral metabolic rate for glucose $\cdot$ FDG: $\left[{ }^{18} \mathrm{~F}\right]-$ fluorodeoxyglucose PET: positron emission tomography . SPM: statistical parametric mapping

\section{Introduction}

In healthy humans, brain glucose supply is maintained by an efficient homeostatic system, which keeps blood glucose concentrations in a narrow range, sufficient to support normal brain function ( $>3 \mathrm{mmol} / \mathrm{l})$ [1]. Incipient hypoglycaemia triggers a cascade of protective responses, including 
suppression of endogenous insulin, stimulation of glucagon secretion and sympatho-adrenal activation, increasing endogenous glucose production and reducing glucose disposal to restore normoglycaemia $[2,3]$. Patients with type 1 diabetes who self-administer insulin frequently experience hypoglycaemia, as insulin levels are determined by their injection regimen and glucagon responses to hypoglycaemia are lost early in the disease [4]. Their main defence against progressive hypoglycaemia is subjective recognition of symptoms such as sweating, tremor and hunger that prompts eating [5]. However, a significant number of patients lose their ability to generate or recognise the symptoms of developing hypoglycaemia [6, 7], developing a syndrome of hypoglycaemia unawareness in which there are no warning symptoms of hypoglycaemia prior to cognitive dysfunction [1], but rapid progression to severe hypoglycaemia with confusion, coma and increased risk of further severe hypoglycaemia [8]. Fear of severe hypoglycaemia limits patients' enthusiasm for the tight glycaemic goals known to protect against diabetic complications and is a limiting factor in achieving good diabetes control [9].

Hypoglycaemia unawareness is associated with delayed onset and reduced magnitude of the neuroendocrine responses to a falling blood glucose $[1,10,11]$. The failure of neuroendocrine activation and symptom perception in hypoglycaemia unawareness is inducible, and reversible, by prior exposure to, and avoidance of, episodes of hypoglycaemia [e.g. 12-16]. Although the mechanisms are unknown, central nervous system detection of the falling blood glucose concentration and initiation of centrally mediated responses are important and attention has focused on changes in cerebral metabolism in hypoglycaemia. Animal data suggest that prior hypoglycaemia upregulates blood-tobrain glucose transport $[17,18]$, limiting the fall in neuronal glucose uptake and metabolism during subsequent hypoglycaemia with failure to trigger counterregulation. In man, studies measuring brain arteriovenous differences have shown preservation of brain glucose uptake with attenuation of the hormonal counterregulatory response during acute hypoglycaemia in models of hypoglycaemia unawareness $[19,20]$. However, other studies have shown no robust preservation of cortical function in hypoglycaemia unawareness $[1,21,22]$, and positron emission tomography (PET) neuroimaging studies have not found evidence for increased brain glucose extraction in acute hypoglycaemia in models of counterregulatory failure [23, 24]. A recent study using magnetic resonance spectroscopy has demon- strated increased glucose content in hypoglycaemia-unaware subjects compared with non-diabetic subjects under conditions of hyperglycaemia $(16.7 \mathrm{mmol} / \mathrm{l})$; however, aware diabetic subjects were not studied, nor were conditions of hypoglycaemia explored [25].

The majority of PET neuroimaging studies use $\left[{ }^{18} \mathrm{~F}\right]$ fluorodeoxyglucose (FDG) as the tracer to model glucose kinetics [26]. FDG is transported and phosphorylated as native glucose, but calculation of glucose uptake and metabolism requires the use of correction factors for each process merged into a lumped constant. Hypoglycaemia affects the correction factors needed in uncertain ways and the calculation of metabolic rate is difficult to estimate at low glucose concentrations with FDG [27]. We set out to examine brain glucose transport in euglycaemia and hypoglycaemia in diabetic men, with PET using ${ }^{11} \mathrm{C}$-labelled 3-O-methyl-D-glucose (CMG), a glucose tracer transported in and out of the cell similarly to glucose, but which is not further metabolised. As there is only a single step involved, the calculation of intracellular glucose concentration (content), rate constants for glucose transport (transport) and, indirectly, glucose phosphorylation (metabolism) are more robust at different glucose concentrations [28-30]. We measured global and regional brain glucose content, transport and metabolism during euglycaemia and hypoglycaemia in hypoglycaemia-aware and -unaware type 1 diabetic men, to examine the brain's glucose metabolic response to hypoglycaemia in the different states of awareness.

\section{Subjects, materials and methods}

\section{Subjects}

Twelve men with type 1 diabetes, six of whom had reduced awareness of hypoglycaemia, were recruited (Table 1). Patients were classified as hypoglycaemia unaware if they (1) reported hypoglycaemic episodes without symptoms; (2) had a history of severe hypoglycaemia in the last 2 years; and (3) had documented more than three episodes of hypoglycaemia (less than $3.5 \mathrm{mmol} / \mathrm{l}$ ) in the absence of symptoms in 56 blood tests made at home over a 2-week period just prior to each study. Patients were classified as hypoglycaemia aware in the absence of the above features $[1,31]$. The 56 home blood tests were requested by the study protocol and, in order to be able to make a valid comparison between the hypoglycaemia experience of all subjects,
Table 1 Patient clinical characteristics

\begin{tabular}{|c|c|c|c|c|c|c|c|}
\hline \multirow[t]{2}{*}{$\begin{array}{l}\text { Patient } \\
\text { group }\end{array}$} & \multirow[t]{2}{*}{$\begin{array}{l}\text { Age } \\
\text { (years) }\end{array}$} & \multirow[t]{2}{*}{ BMI } & \multirow{2}{*}{$\begin{array}{l}\text { Duration } \\
\text { of diabetes } \\
\text { (years) }\end{array}$} & \multirow[t]{2}{*}{$\begin{array}{l}\mathrm{HbA}_{1} \mathrm{c} \\
(\%)\end{array}$} & \multicolumn{3}{|c|}{$\begin{array}{l}\text { Hypoglycaemic episodes } \\
(<3.5 \mathrm{mmol} / 1 \text { over } 2 \text { weeks })\end{array}$} \\
\hline & & & & & Total & $\begin{array}{l}\text { With } \\
\text { symptoms }\end{array}$ & $\begin{array}{l}\text { Without } \\
\text { symptoms }\end{array}$ \\
\hline Aware & $33.8 \pm 9.3$ & $26.2 \pm 3.2$ & $13.7 \pm 7.5$ & $7.6 \pm 1.1$ & 28 & 28 & 0 \\
\hline Unaware & $37.8 \pm 9.1$ & $24.5 \pm 2.4$ & $22.8 \pm 10.9$ & $6.9 \pm 0.7$ & 64 & 10 & 54 \\
\hline
\end{tabular}


additional readings were not used to calculate hypoglycaemia rates. Subjects with a history of ischaemic heart disease, seizures unrelated to hypoglycaemia, unstable retinopathy, nephropathy or any condition requiring regular medication were excluded. All gave written informed consent to participate in the study, which had been approved by ethics committees of King's College Hospital and St Thomas' Hospital London and the UK's Administration of Radioactive Substances Advisory Committee (ARSAC).

\section{Methods}

Subjects were studied twice with a CMG PET scan within a 2- to 8-week period of stable glycaemic control. One scan was conducted during controlled normoglycaemia (plasma glucose $5.0 \mathrm{mmol} / \mathrm{l}$ ), the other during controlled hypoglycaemia $(2.6 \mathrm{mmol} / \mathrm{l})$. The order of the scans was randomised and the subject was blinded to the plasma glucose concentration. On one further occasion, subjects attended for a T1-weighted magnetic resonance image of the brain to co-register with the PET images for anatomical definition. This scan was performed without clamping or specific glucose control.

Subjects were admitted to the unit the night before each PET scan at 20.00h, having eaten dinner and taken their short-acting, but no background, insulin. An intravenous cannula was placed in the antecubital fossa of the dominant arm using aseptic technique and intradermal $1 \%$ lignocaine for anaesthesia. The cannula was kept patent with a slow saline infusion and used for intermittent blood glucose sampling and infusion of soluble insulin. The insulin infusion was adjusted to maintain plasma glucose between 4 and $9 \mathrm{mmol} / \mathrm{l}$. Subjects fasted from $22.00 \mathrm{~h}$.

The following morning, the subject was taken to the Clinical PET Centre and familiarised with the scanning room. After checking for a collateral circulation, a radial arterial catheter for blood sampling was placed in the nondominant hand, using aseptic technique and $1 \%$ lignocaine. A primed continuous infusion of short-acting insulin (Human Actrapid; Novo Nordisk, Copenhagen, Denmark) in a $4 \%$ solution of autologous blood was started through the venous line with a maintenance rate of $1.5 \mathrm{mU} \mathrm{kg}^{-1} \mathrm{~min}^{-1}$. Arterial plasma glucose was measured every $5 \mathrm{~min}$ and maintained at $5 \mathrm{mmol} / \mathrm{l}$ for $1 \mathrm{~h}$ using a variable $20 \%$ glucose infusion (Baxter Healthcare, Thetford, UK) [32]. During this time, the subject was moved into the scanning room and made comfortable on the scanning table. Plasma glucose was either maintained at $5 \mathrm{mmol} / \mathrm{l}$ for the remainder of the study or reduced to $2.6 \mathrm{mmol} / \mathrm{l}$ prior to injection of the PET tracer (see below) and during the remainder of the study.

At the end of the study, insulin was discontinued and euglycaemia restored. The subject was given lunch and a modified dose of subcutaneous insulin. When plasma glucose was stable, all lines were removed and the subject was allowed home. Each subject was advised to monitor blood glucose carefully and warned of the risk of further hypoglycaemic episodes over the next 24-48 h.
Scanning protocol

Images were acquired using a CTI ECAT 951R scanner, axial field view $10.8 \mathrm{~cm}$, in-plane spatial resolution $6.5 \mathrm{~mm}$ (CTI/Siemens, Knoxville, TN, USA). The subject's head was aligned axially to the orbitomeatal line and secured with a restraining strap. The head position was monitored using a laser grid. Sensory disturbance was standardised by studying subjects with their eyes shut and in background scanner noise. Prior to injection of tracer, a 2-min transmission scan was performed to confirm correct positioning, followed by a 10 -min transmission scan for photon attenuation correction. Once plasma glucose had reached the target level, a single dose of $131 \pm 40 \mathrm{MBq}$ of $\left[{ }^{11} \mathrm{C}\right]-3-O-$ methyl glucose diluted up to $10 \mathrm{ml}$ with normal saline was injected over $10 \mathrm{~s}$ through the venous line and flushed with $10 \mathrm{ml}$ of normal saline. The time lag between achieving the target hypoglycaemia and tracer injection was $12 \min 5 \mathrm{~s} \pm 15$ min $20 \mathrm{~s}$, with no significant differences between the aware and unaware. Dynamic scanning was started $10 \mathrm{~s}$ prior to injection of the tracer, taking 60 frames over $60 \mathrm{~min}$, initially at 2-s frames, increasing to $300-\mathrm{s}$ frames. Continuous online blood sampling to detect tracer levels in arterial blood was started $1 \mathrm{~min}$ prior to tracer injection at a rate of $5 \mathrm{ml} / \mathrm{min}$ for $15 \mathrm{~min}$, then $2 \mathrm{ml} / \mathrm{min}$ for a further $15 \mathrm{~min}$ (IVAC 572 peristaltic pump; Eli Lilly, San Diego, CA, USA) using blood drawn through a BGO Crystal Fluid Analyser (Allogg, Stockholm, Sweden). Timed 2-ml handdrawn arterial blood samples were taken every $5 \mathrm{~min}$ for cross-calibration of the fluid analyser with a well counter calibrated to the scanner and also for measurement of plasma glucose concentrations. The fluid analyser data and the timed blood samples were used to derive an arterial plasma input function for each study. PET images were reconstructed by filtered back-projection and smoothed with a Hanning 0.5 filter, resulting in a spatial resolution of $8.5 \mathrm{~mm}$ full width at half maximum transaxially and axially. Reconstructed images were displayed in a $128 \times 128 \times 31$ voxel format, each voxel measuring $2.0 \times 2.0 \times 3.37 \mathrm{~mm}$.

\section{CMG production}

$\left[{ }^{11} \mathrm{C}\right]-3-O-M e t h y l$ glucose was synthesised by methylation of the diacetone-D-glucose potassium salt (precursor) with $\left[{ }^{11} \mathrm{C}\right]$-methyl iodide using the fully automated SYNTHIA system [33]. Briefly, $7 \mathrm{mg}$ of the precursor in $300 \mu \mathrm{l}$ acetonitrile was reacted at $70^{\circ} \mathrm{C}$ for $5 \mathrm{~min}$. After methylation, the product was transferred to the rotary evaporator in SYNTHIA and evaporated to dryness. The residue was resolubilised in $2 \mathrm{ml}$ of $1 \mathrm{~mol} / \mathrm{l} \mathrm{HCl}$ and hydrolysed at $120^{\circ} \mathrm{C}$ for $12 \mathrm{~min}$. The acid solution was transferred to an ion retardation column containing AG11A8 resin and subsequently eluted through three C-18 SepPaks. The resin and C-18 SepPaks were flushed with $6 \mathrm{ml}$ sterile water and the product passed through a $0.22 \mu \mathrm{m}$ filter. The product was analysed using reversed-phase HPLC with online UV and radioactivity detection. $\left[{ }^{11} \mathrm{C}\right]-3-O-$-Methyl glucose was synthesised with a radiochemical purity $>95 \%$. 


\section{Biochemical analyses}

Plasma glucose was measured using a glucose oxidasetechnique (Yellow Springs Instruments, Yellow Springs, $\mathrm{OH}$, USA). Catecholamines were measured using highpressure liquid chromatography with electrochemical detection [34]. Plasma insulin, cortisol and growth hormone were measured by radioimmunoassay (Diagnostic Systems Laboratories, London, UK) with inter- and intra-assay variabilities of $<10 \%$ for all.

Image analysis: calculation of whole-brain glucose transport, content and metabolism

The rates of glucose transport from brain capillaries to brain tissue were calculated using a standard two-compartment model of CMG kinetics, where one compartment represents CMG concentration in the capillaries and the other the concentration in brain tissue [35, 36]. The transport process is saturable, with substrate flowing both ways between compartments, and can be described by Michaelis-Menten enzyme kinetics [37]. The transport rates $K_{1}$ and $k_{2}$, into and out of brain tissue respectively, were calculated by obtaining the parameters of a fit of the brain and blood time-activity curves to the two-compartment model. Non-linear fits based on the LevenbergMarquardt method were performed using the Compartment Model Kinetic Analysis Tool (COMKAT) [38].

Whole-brain analysis was performed as follows. The activity in all brain image slices was averaged, after application of a $50 \%$ threshold to exclude non-cerebral activity, resulting in a single activity-time curve. The CMG concentration in the capillary plasma, $C_{\mathrm{p}}$, was obtained from the arterial blood samples. Total activity in the brain represents the brain tissue compartment $C_{\mathrm{b}}$ plus a small contribution $(\sim 5 \%)$ from brain capillaries. This contribution is equal to a fraction, $f_{\mathrm{v}}$, of the concentration in the whole arterial blood, $C_{\mathrm{a}}$. According to the two-compart- ment model, the brain time-activity curve, $C_{\mathrm{PET}}(t)$, can therefore be described by the following equation [30]:

$C_{\mathrm{PET}}(t)=\left(1-f_{\mathrm{v}}\right) K_{1} C_{\mathrm{p}}(t) \otimes \exp \left(-k_{2} t\right)+f_{\mathrm{v}} C_{\mathrm{a}}(t)$

The parameters proved to be stable with respect to the starting values used in the fitting algorithm and the fits of the model to the data were good $(p<0.001, F(2,57)>3000)$.

As transport rates for CMG are proportional to those of D-glucose, Michaelis-Menten kinetics can be applied to derive brain glucose concentration, $M_{\mathrm{e}}$, and cerebral metabolic rate for glucose, CMRglc [35].

$M_{\mathrm{e}}=\left(K_{1} / k_{2}\right)\left(K_{t}+C_{\mathrm{a}, \mathrm{G}}\right)-K_{t} S$

$\mathrm{CMRglc}=\left(k_{2} S-K_{1}\right) K_{t}$

$C_{\mathrm{a}, \mathrm{G}}$ represents the measured arterial glucose concentration, $K_{t}$ is the Michaelis-Menten constant (the concentration at which the flux is half the saturation value) and $S$ is the volume of distribution. $S$ was assumed to be $0.77 \mathrm{ml} / \mathrm{g}$ [29]. The mean value of $K_{t}=4.05$, as collated by Gruetter et al., was used [39].

\section{Statistical analysis}

All results are given as mean $\pm \mathrm{SD}$. The baseline characteristics of the subject groups were compared using an unpaired Student's $t$-test. SPSS 11 (SPSS, Woking, UK) was used for group and condition analysis by repeatedmeasures ANOVA. For the primary hypothesis (differences in CMRglc by group and condition), values of $p<0.05$ were considered significant. For additional comparisons, the threshold for significance was adjusted for multiple comparisons. During the scanning of one aware subject there

Table 2 Neuroendocrine measurements presented as the area under the curve over the 60-min scan

\begin{tabular}{|c|c|c|c|c|c|c|c|}
\hline \multirow[t]{2}{*}{ Endocrine } & \multicolumn{2}{|c|}{ Euglycaemia } & \multicolumn{2}{|c|}{ Hypoglycaemia } & \multicolumn{2}{|l|}{ Main effect } & \multirow[t]{2}{*}{ Interaction } \\
\hline & Aware & Unaware & Aware & Unaware & Group & Condition & \\
\hline \multirow[t]{2}{*}{ Adrenaline $\left(\mathrm{nmol} \mathrm{l}^{-1} \mathrm{~h}^{-1}\right)$} & $3.18^{\mathrm{a}}$ & $1.82^{\mathrm{a}}$ & $17.61^{\mathrm{a}}$ & $12.57^{\mathrm{a}}$ & $p=0.346^{\mathrm{c}}$ & $p=0.00033^{\mathrm{c}}$ & $p=0.453^{\mathrm{c}}$ \\
\hline & $2.59^{\mathrm{b}}$ & $0.95^{\mathrm{b}}$ & $11.60^{\mathrm{b}}$ & $7.08^{\mathrm{b}}$ & $F(1,10)=0.976$ & $F(1,10)=28.55$ & $F(1,10)=0.611$ \\
\hline \multirow[t]{2}{*}{ Noradrenaline $\left(\mathrm{nmol} \mathrm{l} \mathrm{l}^{-1} \mathrm{~h}^{-1}\right)$} & $9.11^{\mathrm{a}}$ & $9.01^{\mathrm{a}}$ & $14.20^{\mathrm{a}}$ & $9.91^{\mathrm{a}}$ & $0.299^{\mathrm{c}}$ & $0.0413^{\mathrm{c}}$ & $0.133^{\mathrm{c}}$ \\
\hline & $2.13^{\mathrm{b}}$ & $4.19^{\mathrm{b}}$ & $6.29^{\mathrm{b}}$ & $2.49^{\mathrm{b}}$ & 1.199 & 5.480 & 2.670 \\
\hline \multirow[t]{2}{*}{ Growth hormone $\left(\mathrm{U} \mathrm{l}^{-1} \mathrm{~h}^{-1}\right)$} & $43.5^{\mathrm{a}}$ & $190.0^{\mathrm{a}}$ & $468.7^{\mathrm{a}}$ & $388.3^{\mathrm{a}}$ & $0.753^{\mathrm{c}}$ & $0.00714^{\mathrm{c}}$ & $0.228^{\mathrm{c}}$ \\
\hline & $33.3^{\mathrm{b}}$ & $185.4^{\mathrm{b}}$ & $301.1^{\mathrm{b}}$ & $227.5^{\mathrm{b}}$ & 0.106 & 12.85 & 1.702 \\
\hline \multirow[t]{2}{*}{ Cortisol (nmol l-1 $\left.\mathrm{h}^{-1}\right)$} & $2,499^{\mathrm{a}}$ & $2,578^{\mathrm{a}}$ & $3,922^{\mathrm{a}}$ & $3,182^{\mathrm{a}}$ & $0.498^{\mathrm{c}}$ & $0.00666^{\mathrm{c}}$ & $0.198^{\mathrm{c}}$ \\
\hline & $456^{\mathrm{b}}$ & $1,014^{\mathrm{b}}$ & $1,340^{\mathrm{b}}$ & $823^{b}$ & 0.494 & 11.63 & 1.902 \\
\hline
\end{tabular}

\footnotetext{
${ }^{\mathrm{a}}$ Mean values

${ }^{\mathrm{b}}$ Standard deviations

c $p$-values for $F$ scores
} 


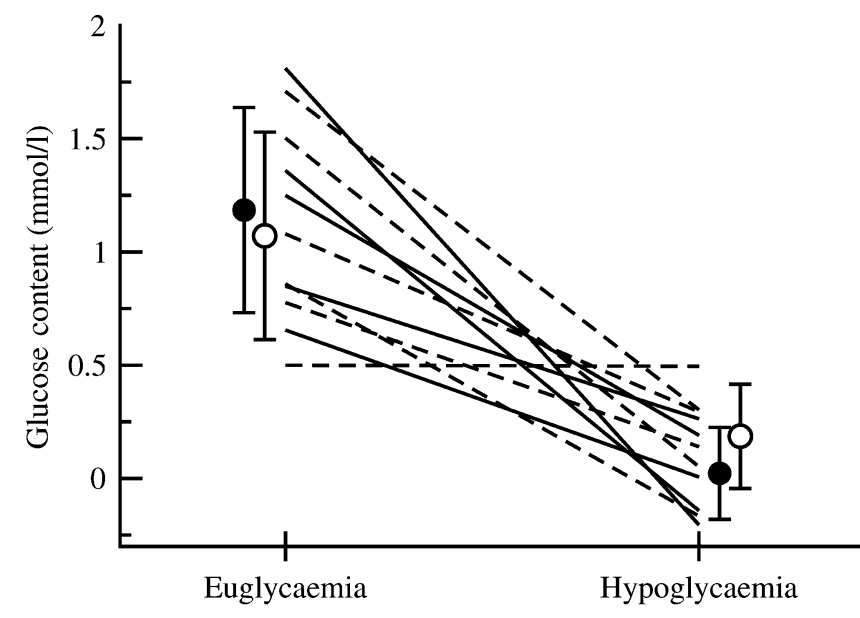

Fig. 1 Whole-brain glucose content under conditions of euglycaemia and hypoglycaemia. Data are presented for individuals and as mean and SD for each group. Solid circles and solid lines, hypoglycaemia-aware subjects, $n=5$; open circles and dashed lines, hypoglycaemia-unaware subjects, $n=6$

was a failure of the fluid analyser, requiring hand-timed samples to be taken, and global quantitative data could not be obtained from this subject, who was excluded from regional and qualitative analyses.

\section{Regional brain CMG uptake}

Regional differences in brain CMG uptake between groups and conditions were identified using statistical parametric mapping (SPM2; available from http://www.fil.ion.ucl.ac. uk). PET images were transformed into standardised anatomical space by linear and non-linear transformation to the standard Montreal Neurological Institute (MNI) template to allow interparticipant averaging and comparison. Smoothing was performed on all scans using an isotropic Gaussian kernel of $20 \mathrm{~mm}$ in order to allow for differences in gyral anatomy between individuals and to increase signal to noise ratios $[40,41]$, and search volume was restricted to grey matter regions using the MNI template provided. Figure 3, the tracer uptake from one subject, confirms that uptake was primarily in grey matter. The effect of interindividual variance in scans resulting from differing injected doses and cerebral distribution was removed using proportional weighting. The analysis was conducted by definition of the appropriate linear contrasts within a group by condition design matrix. Comparisons of group, condition and their interaction were made by definition of the appropriate linear contrasts. Clusters of more than 100 voxels that survived a threshold peak $Z$ score of $>3.09(p<0.001)$ were considered to show a significant difference, and lower thresholds were employed to exclude type 2 (false-negative) errors.

\section{Results}

Glucose, insulin, hypoglycaemia awareness and hormone responses

During the 2-week monitoring period, more than $95 \%$ of the requested home blood tests were recorded in both groups. All subjects in the aware group were aware of all episodes of blood glucose $<3.5 \mathrm{mmol} / \mathrm{l}$. The unaware group recorded more frequent hypoglycaemia and were aware of very few of these (Table 1). Apart from their hypoglycaemia experience, however, the groups were not significantly different in terms of age, duration of diabetes or $\mathrm{HbA}_{1} \mathrm{c}$. During the clamps, steady-state free insulin levels were $58 \pm 24$ and $69 \pm$ $38 \mathrm{mU} / 1$ ( $p=\mathrm{NS}$ ) during euglycaemic and hypoglycaemic

Table 3 Tracer kinetic modelling results for whole brain

\begin{tabular}{|c|c|c|c|c|c|c|c|}
\hline \multirow[t]{2}{*}{ Parameter } & \multicolumn{2}{|c|}{ Euglycaemia } & \multicolumn{2}{|c|}{ Hypoglycaemia } & \multicolumn{2}{|l|}{ Main effect } & \multirow[t]{2}{*}{ Interaction } \\
\hline & Aware & Unaware & Aware & Unaware & Group & Condition & \\
\hline \multirow{2}{*}{$K_{1}\left(\mathrm{ml} \mathrm{g}^{-1} \min ^{-1}\right)$} & $0.0461^{\mathrm{a}}$ & $0.0477^{\mathrm{a}}$ & $0.0561^{\mathrm{a}}$ & $0.0470^{\mathrm{a}}$ & $p=0.494^{\mathrm{c}}$ & $p=0.380^{\mathrm{c}}$ & $p=0.323^{\mathrm{c}}$ \\
\hline & $0.0039^{\mathrm{b}}$ & $0.0157^{\mathrm{b}}$ & $0.0167^{b}$ & $0.0062^{b}$ & $F(1,9)=0.507$ & $F(1,9)=0.851$ & $F(1,9)=1.092$ \\
\hline \multirow[t]{2}{*}{$k_{2}(1 / \min )$} & $0.0978^{\mathrm{a}}$ & $0.1018^{\mathrm{a}}$ & $0.1176^{\mathrm{a}}$ & $0.0937^{\mathrm{a}}$ & $0.268^{\mathrm{c}}$ & $0.474^{\mathrm{c}}$ & $0.104^{c}$ \\
\hline & $0.0067^{\mathrm{b}}$ & $0.0233^{b}$ & $0.0285^{\mathrm{b}}$ & $0.0073^{b}$ & 1.394 & 0.559 & 3.260 \\
\hline \multirow[t]{2}{*}{$K_{1} / k_{2}(\mathrm{ml} / \mathrm{g})$} & $0.473^{\mathrm{a}}$ & $0.462^{\mathrm{a}}$ & $0.472^{\mathrm{a}}$ & $0.500^{\mathrm{a}}$ & $0.557^{\mathrm{c}}$ & $0.388^{\mathrm{c}}$ & $0.383^{\mathrm{c}}$ \\
\hline & $0.048^{\mathrm{b}}$ & $0.051^{\mathrm{b}}$ & $0.032^{\mathrm{b}}$ & $0.033^{\mathrm{b}}$ & 0.372 & 0.824 & 0.843 \\
\hline \multirow{2}{*}{$\begin{array}{l}\text { CMRglc } \\
\left(\mu \mathrm{mol} 100 \mathrm{~g}^{-1} \mathrm{~min}^{-1}\right)\end{array}$} & $11.84^{\mathrm{a}}$ & $12.46^{\mathrm{a}}$ & $13.96^{\mathrm{a}}$ & $10.16^{\mathrm{a}}$ & $0.053^{\mathrm{c}}$ & $0.927^{\mathrm{c}}$ & $0.043^{\mathrm{c}}$ \\
\hline & $2.43^{\mathrm{b}}$ & $1.94^{\mathrm{b}}$ & $2.37^{\mathrm{b}}$ & $0.80^{\mathrm{b}}$ & 4.937 & 0.009 & 5.567 \\
\hline \multirow[t]{2}{*}{ Content (mmol/l) } & $1.185^{\mathrm{a}}$ & $1.071^{\mathrm{a}}$ & $0.022^{\mathrm{a}}$ & $0.186^{\mathrm{a}}$ & $0.853^{\mathrm{c}}$ & $0.0002^{\mathrm{c}}$ & $0.441^{\mathrm{c}}$ \\
\hline & $0.453^{\mathrm{b}}$ & $0.459^{\mathrm{b}}$ & $0.203^{\mathrm{b}}$ & $0.230^{\mathrm{b}}$ & 0.036 & 35.385 & 0.650 \\
\hline \multirow{2}{*}{$\begin{array}{l}\text { Tracer uptake per } \\
\text { voxel per second, } \\
\text { corrected by dose } \\
\text { and body weight }\end{array}$} & $806.5 \times 10^{-6} \mathrm{a}$ & $864.2 \times 10^{-6 \mathrm{a}}$ & $842.3 \times 10^{-6} \mathrm{a}$ & $835.9 \times 10^{-6} \mathrm{a}$ & $0.724^{\mathrm{c}}$ & $0.976^{\mathrm{c}}$ & $0.792^{\mathrm{c}}$ \\
\hline & $171.2 \times 10^{-6} \mathrm{~b}$ & $377.4 \times 10^{-6 b}$ & $126.8 \times 10^{-6 \mathrm{~b}}$ & $200.1 \times 10^{-6} \mathrm{~b}$ & $F=0.132$ & 0.001 & 0.073 \\
\hline
\end{tabular}

${ }^{\mathrm{a}}$ Mean values

${ }^{\mathrm{b}}$ Standard deviations

${ }^{c} p$-values for $F$ scores 


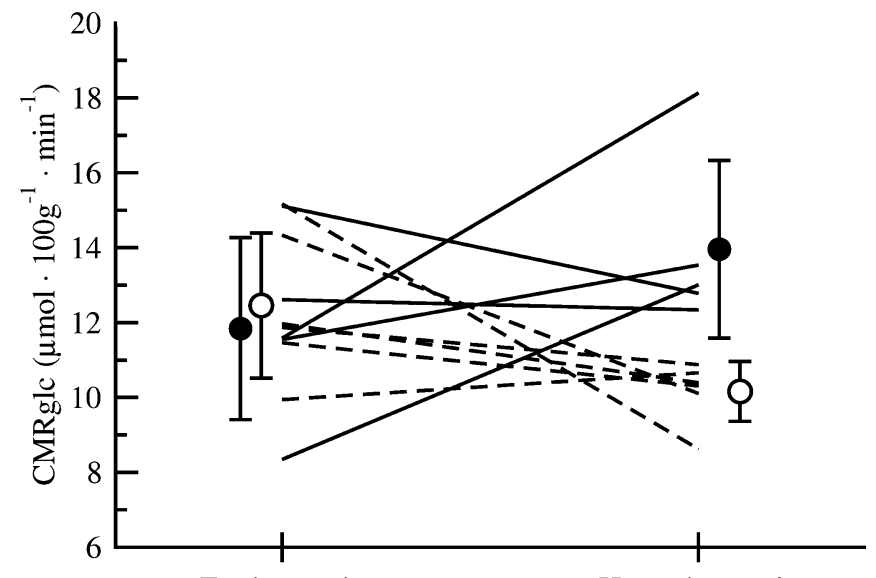

Euglycaemia

Fig. 2 Whole-brain glucose metabolic rate under conditions of euglycaemia and hypoglycaemia. Data are presented for individuals and as mean and SD for each group. Solid circles and solid lines, hypoglycaemia-aware subjects; open circles and dashed lines, hypoglycaemia-unaware subjects

studies. Mean plasma glucose was $5.0 \pm 0.1 \mathrm{mmol} / 1$ in the aware vs. $5.0 \pm 0.1 \mathrm{mmol} / \mathrm{l}$ in the unaware subjects $(p=\mathrm{NS})$ during euglycaemic studies and $2.6 \pm 0.0$ vs. $2.6 \pm 0.1 \mathrm{mmol} / 1$ ( $p=\mathrm{NS}$ ) during hypoglycaemic studies.

All the aware subjects correctly identified each study as eu- or hypoglycaemic, reported symptoms of hypoglycaemia and were observed to sweat by two observers during the hypoglycaemic clamps only. In contrast, the members of the unaware group were unsure or unaware of the hypoglycaemic study, reported no hypoglycaemic symptoms and were observed not to sweat.

Adrenaline, noradrenaline, growth hormone and cortisol levels were not different between groups during the run-in or at euglycaemia (Table 2). All four hormones showed a significant rise during hypoglycaemia. Differences between the two patient groups did not achieve statistical significance.

Whole-brain glucose content, glucose transport and CMRglc

Whole-brain glucose content fell significantly in both groups ( $p=0.0002$ compared with the threshold of significance with four independent null hypotheses, 0.0127) between euglycaemia and hypoglycaemia (aware, 1.18 \pm 0.45 to $0.02 \pm 0.2 \mathrm{mmol} / \mathrm{l}$; unaware, $1.07 \pm 0.46$ to $0.19 \pm 0.23$ $\mathrm{mmol} / \mathrm{l}$ ), with no significant difference between groups (Fig. 1) (Table 3). Brain glucose transport parameters were not significantly different within or between the groups at euglycaemia or hypoglycaemia (Table 3 ). In contrast, a significant group by condition interaction was observed in whole-brain CMRglc, with a rise in the aware group $(11.839 \pm 2.432$ to $13.958 \pm 2.372)$ vs a fall in the unaware group (12.457 \pm 1.938 to $\left.10.16 \pm 0.801 \mu \mathrm{mol} 100 \mathrm{~g}^{-1} \mathrm{~min}^{-1}\right)$ at hypoglycaemia $(p=0.043)$. Post hoc analysis revealed that CMRglc at hypoglycaemia was significantly lower in the unaware than in the aware (unaware, $10.2 \pm 0.8$; aware, $14.0 \pm 2.4 \mu \mathrm{mol} 100 \mathrm{~g}^{-1} \mathrm{~min}^{-1} ; p=0.02$ ) (Fig. 2). No significant correlations between neuroendocrine response and CMRglc were observed for adrenaline $(r=0.0005$, $p=0.998)$, noradrenaline $(r=0.17, p=0.44)$, growth hormone $(\mathrm{r}=-0.10, p=0.68)$ or cortisol $(r=-0.12, p=0.59)$.

\section{Regional analyses}

Representative axial images of CMG uptake summed over all time frames are shown in Fig. 3, which shows that tracer uptake was primarily in grey matter. SPM analysis high-
Fig. 3 Cerebral distribution of $\left[{ }^{11} \mathrm{C}\right]-3-O$-methyl-D-glucose in a typical subject. Axial slices are shown in descending order from cerebral vertex (top left) to cerebellum and inferior frontal and temporal cortex (bottom right) and demonstrate tracer uptake in the cortical mantle and subcortical grey matter, sparing white matter
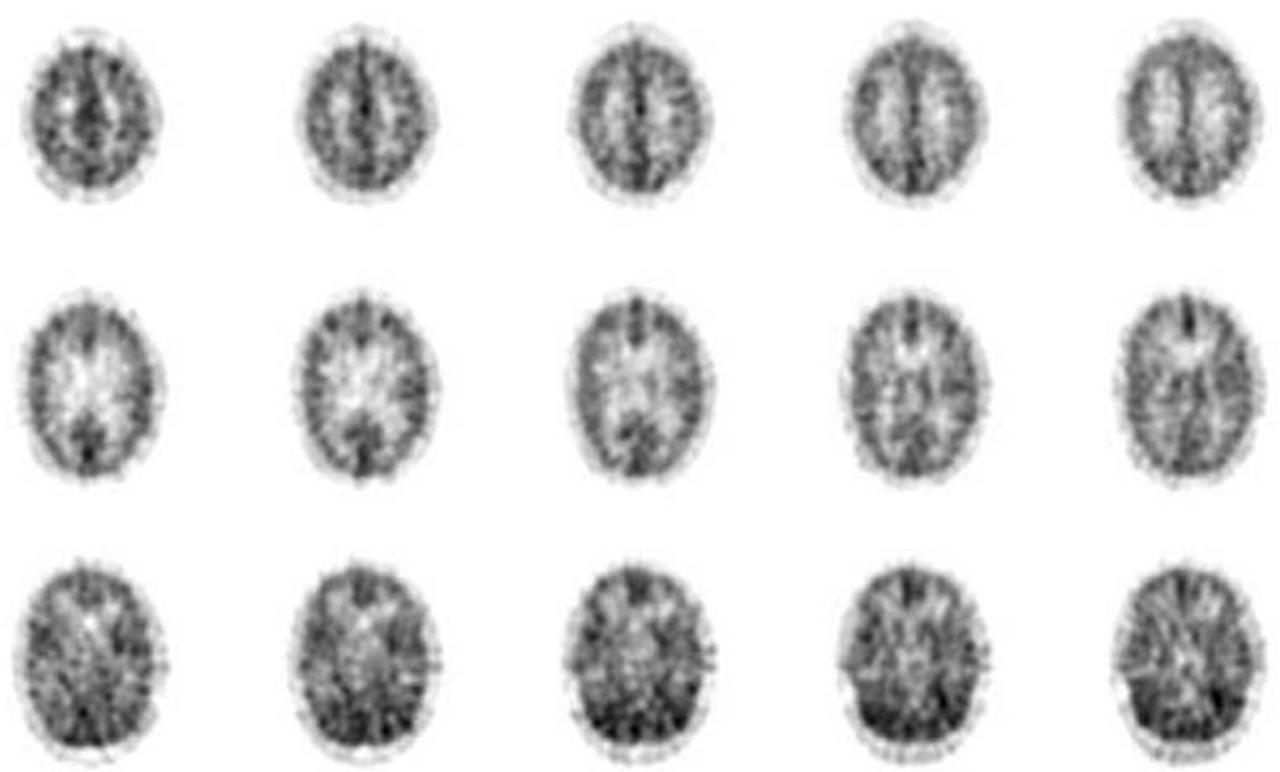

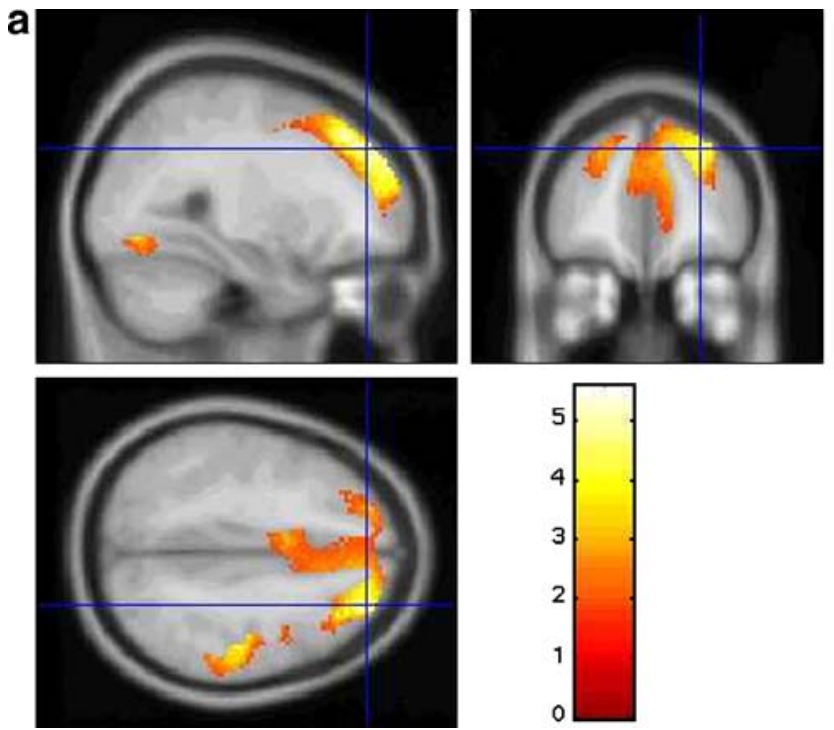

Fig. 4 Statistical parametric mapping results registered to an averaged T1 magnetic resonance image. The orange colour (a) indicates a statistically significant increase. Blue (b) indicates a statistically significant decrease in tracer uptake, relative to wholebrain values, between euglycaemia and hypoglycaemia (all subjects, $n=6$ in each group) at a threshold of $p<0.05$. Increased tracer uptake

lighted areas where relative CMG uptake differed between euglycaemia and hypoglycaemia (Fig. 4). One prefrontal cortical region showed relatively increased uptake for both groups during hypoglycaemia. This included Brodmann area 10 in the right dorsolateral prefrontal cortex (Talairach coordinates of maximal effect, $x, y$ and $z=24,30,48$ respectively, corrected $[p<0.001, Z=3.84]$ and a cluster size of 227). At a lower height threshold of $p<0.05$, which provides improved type 2 error control, this region was revealed to extend bilaterally to the left dorsolateral prefrontal cortex across midline frontal regions, including the anterior cingulate gyrus (Brodmann area 32; Fig. 4, top). Finally, a region encompassing the midline occipital cortex and cerebellar vermis showed relatively decreased CMG uptake in both groups during hypoglycaemia (Brodmann area 17; Talairach coordinates of maximal effect, $x, y$ and $z=4,-96,4$ respectively, corrected $[p<0.001, Z=3.89]$, cluster size 127) (Fig. 4, bottom). Group $\times$ condition interaction contrasts failed to reveal any suprathreshold regional effects.

\section{Discussion}

We used CMG PET to investigate changes in global and regional brain glucose metabolism between euglycaemia and hypoglycaemia in aware and unaware diabetic subjects. Our major positive findings are a decrease in global brain glucose content with hypoglycaemia in both groups of subjects and a difference in the change in brain glucose metabolic rate with hypoglycaemia between the aware and unaware.

The demonstration of a significant fall in global brain glucose content during acute moderate hypoglycaemia in
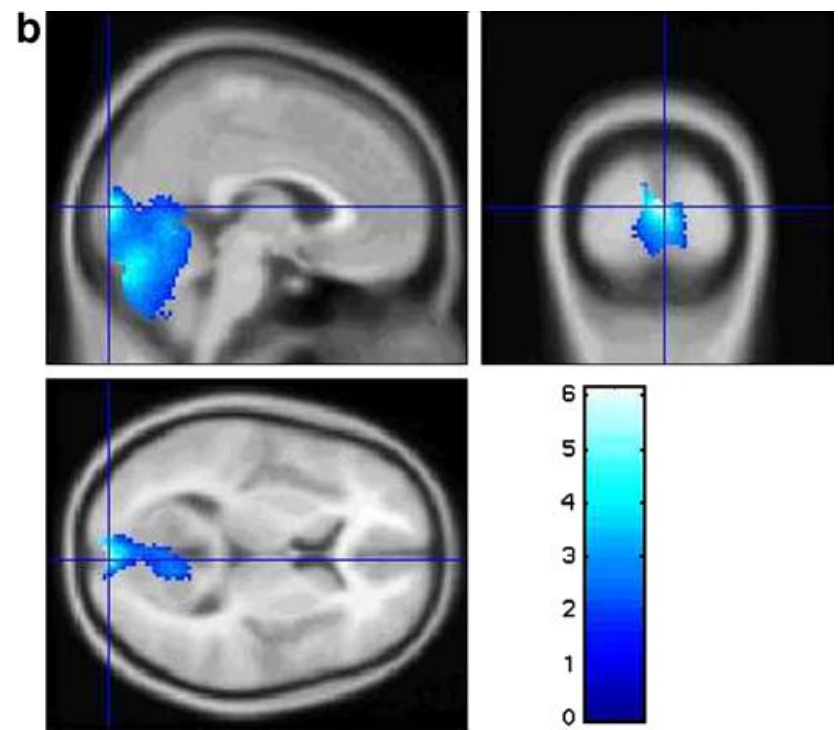

is shown in a contiguous region involving Brodmann area 10 (an area which survived analysis at $p=0.001$ and minimum cluster size of 100 voxels; data not shown) and anterior cingulate cortex. Decreased tracer uptake is shown in a contiguous region involving Brodmann area 17 and cerebellar vermis

men with type 1 diabetes mellitus is novel and presumably reflects depletion of neuronal-glial glucose under conditions of restricted glucose. This finding is logical and serves to validate the methodology of our study.

The lack of a difference in global brain glucose content between the subjects with and without awareness of hypoglycaemia (both by history and during the hypoglycaemia of the study) was unexpected, in view of animal data suggesting upregulation of glucose transporters in models of recurrent hypoglycaemia [17, 18] and the studies of hypoglycaemia-accustomed human subjects in whom brain glucose uptake at hypoglycaemia was calculated from arteriovenous differences and blood flow $[19,20]$. In the present study, we also found no differences in the rate constants for tracer inflow $\left(K_{1}\right)$ and outflow $\left(k_{2}\right)$ with respect to group (aware or unaware), condition (euglycaemia or hypoglycaemia) or in the interaction between group and condition. We noted high variability in $k_{2}$ (rate constant for glucose outflow) between individuals, as previously reported [35]. Our study is small and a type 2 error is possible, reflecting the relatively low signal-to-noise ratio in the data when regional analysis is employed in comparison with FDG. However, power calculations suggest we should have detected any difference greater than $15 \%$ between the two groups in $K_{1} / k_{2}$ ratio measures in the present study, and our data are supported by an earlier PET study which failed to find any change in brain glucose transport rates in a human model of hypoglycaemia unawareness [23]. Thus, if upregulation of glucose transport does occur its net global effect should be less than this. Furthermore, our data are consistent with: (1) earlier PET studies using FDG which failed to find any evidence for upregulation of glucose uptake in hypoglycaemia-accustomed and -unaware diabetic subjects, either basally [24] 
or at modest hypoglycaemia [25]; (2) the negative study in hypoglycaemia-naive and hypoglycaemia-accustomed healthy volunteers using ${ }^{11} \mathrm{C}$ PET [23]; and (3) data failing to find downregulation of glucose transport in poorly controlled diabetes [42, 43]. All these data support an explanation for unawareness that is not dependent on upregulation of neuronal glucose uptake, such as increased efficiency of use of non-glucose metabolic fuels.

The major difference between our groups was in the changes in global metabolic rate for glucose with hypoglycaemia, with a relative rise from the rate at euglycaemia in the aware subjects and a relative fall in the unaware, the difference between the responses of the two groups being significant $(p<0.043)$. These data represent a significant extension of: (1) our earlier FDG study, in which we were unable to measure the effect of hypoglycaemia on the above parameters due to the limitations of FDG kinetic modelling [24]; and (2) the PET study of Segel et al., in which brain glucose metabolic parameters were measured at a plasma glucose of $3.6 \mathrm{mmol} / \mathrm{l}$, at which level neither hypoglycaemia-accustomed or -unaccustomed subjects would experience symptoms [23]. These data offer a potential new insight into the phenomenon of unawareness. The lack of evidence in our data for relative preservation of brain glucose content or metabolism in the unaware group is consistent with the lack of protection for cortical function during hypoglycaemia in hypoglycaemia unawareness [1], but does not explain why the onset of neuroendocrine and symptom responses is delayed $[1,21,22]$ or the modest preservation of some cortical functions seen in some studies [e.g. 22]. In contrast, the differential response of CMRglc to hypoglycaemia seen in the present data offer a different explanation for the lack of awareness in the unaware group. In PET studies of this nature, a rise in CMRglc reflects neuronal activation [44]. The observed rise in CMRglc in the aware group with hypoglycaemia relative to the unaware can therefore be interpreted as a measurable activation of the cerebral cortices, underlying the generation and perception of subjective awareness. Such an interpretation uses classical functional imaging concepts, in that activation of neurones is implied by the demonstration of increased perfusion or, as in this case, metabolism in the relevant brain area. A similar pattern of cerebral response is reported in studies examining levels of emotional arousal and awareness [44]. The lack of increase in CMRglc with hypoglycaemia in the unaware subjects is interpretable as a failure of neuronal activation with hypoglycaemia in that group. These data suggest that functional changes in cortical activation underlie the loss of awareness of hypoglycaemia, rather than a simple change in the metabolic capacity of the cortical neurones. Our measures of symptoms during the scans were not sufficiently robust for us to attempt a direct correlation between change in cortical CMRglc and symptom intensity; further studies may attempt this.

The difference between hormonal responses, especially adrenaline, between the aware and unaware diabetic subjects was less marked than in previous studies of this nature and may suggest that our unaware patient group was not typical of the syndrome. This is unlikely, as the subjects were characterised prospectively by established criteria $[1$, 31], and characterisation was confirmed at the time of study by the total absence of subjective recognition of hypoglycaemia and sweating during hypoglycaemic clamps in the unaware subjects, with $100 \%$ correct identification of hypoglycaemia and observed sweating by the aware subjects. The differences in subjective responses to the study hypoglycaemia also rules out the possibility of a major effect of any coincidental hypoglycaemia in the week before the study in the aware group, although, in contrast, the deliberate avoidance of hypoglycaemia the night prior to study in our protocol will have worked against us in possibly reducing the normal hypoglycaemia exposure of the unaware. The significant association of CMRglc with the absence of subjective awareness offers further support for the correct classification of our patients. That adrenergic activation during hypoglycaemia to some degree occurred in both groups is evidenced by the regional relative increase in CMG glucose uptake found by SPM analysis to extend to the anterior cingulate in both groups, as this brain region is associated with autonomic activation [45]. Because our analysis corrects for global differences between scans prior to seeking regional differences, we cannot identify whether neuronal activation in the anterior cingulate was relatively attenuated in the unaware group, although the global CMRglc data would be consistent with this hypothesis. A larger study may be needed to investigate regional differences in brain activation associated with significant differences in the hormonal responses to hypoglycaemia. Furthermore, the scanning procedures may provide a background state of arousal that makes it more difficult to detect differences in the adrenaline responses to hypoglycaemia between groups. However, our data are consistent with other studies in which hormonal responses and awareness have not been concordant and provide further evidence that adrenaline responses per se do not define hypoglycaemia unawareness [e.g. 46, 47].

Our regional analyses described increased relative $\mathrm{CMG}$ uptake in Brodmann area 10 during hypoglycaemia in both groups. This regional increase survived high type 1 error control and, with improved type 2 error control, extended bilaterally and to the midline anterior cingulate as a contiguous region. We interpret this regional increase in uptake to reflect activation of brain regions concerned with the monitoring of internal state, as has recently been identified in regional cerebral blood flow studies of hypoglycaemia which identify strong and unequivocal activation in the anterior cingulate cortex [48]. While the dorsolateral prefrontal cortex is concerned with working memory processing and engages in a variety of working memory tasks [49], attention and working memory are cerebral functions susceptible to impairment during hypoglycaemia [50]. The increase in relative $\mathrm{CMG}$ uptake in this region is puzzling, but may reflect diversion of processing resources to the monitoring of internal state from conscious working memory processes. The reduction in relative CMG uptake identified in regions of occipital cortex and cerebellum probably reflects deactivation of these regions during hypoglycaemia. The occipital cortical region is centred on the striate visual cortex, con- 
cerned with primary visual processing, and colour vision and visual discrimination are known to be impaired during hypoglycaemia [51]. Similarly, impairment in function of the cerebellar vermis may lead to decrement, not only in motor function and coordination, but in cognitive, predominantly executive, processes [52].

In conclusion, CMG PET reliably measures whole-brain glucose content and metabolism, showing a fall in global brain glucose content during hypoglycaemia in man. We have identified differences in glucose handling in brain regions associated with visual processing, coordination, working memory, attention and autonomic function during hypoglycaemia in both hypoglycaemia-aware and -unaware diabetic patients, all functions known to be affected by hypoglycaemia. We have demonstrated global neuronal activation at hypoglycaemia in hypoglycaemia-aware patients, a response absent in the unaware, suggesting that cortical activation is a necessary correlate of the state of hypoglycaemia awareness. These findings fit with clinical presentations of acute hypoglycaemia and are worthy of further investigation.

Acknowledgements This study was funded by a project grant from the Juvenile Diabetes Research Foundation International. E.M.B. was a Royal College of Physicians of London BUPA Fellow. We thank Andrew Pernet and Bula Wilson who provided nursing support; PET technicians Bernadette Cronin and Nigel Benatar and the staff at St Thomas' Clinical PET Centre; and Dr Jenny Jones and Professor Ian Macdonald for the laboratory assays. Finally we thank the patients who kindly volunteered to take part in the study.

\section{References}

1. Maran A, Lomas J, MaccDonald IA, Amiel SA (1995) Lack of preservation of higher brain function during hypoglycaemia in patients with intensively treated insulin dependent diabetes mellitus. Diabetalogia 38:1412-1418

2. Rizza RA, Cryer PE, Gerich JE (1979) Role of glucagon, catecholamines and growth hormone in human glucose counterregulation. J Clin Invest 64:62-71

3. Mitrakou A, Ryan C, Veneman T et al (1991) Hierarchy of glycaemic thresholds for counterregulatory hormone secretion, symptoms and cerebral dysfunction. Am J Physiol 260:E67E74

4. Bolli G, de Feo P, Compagnucci P et al (1983) Abnormal glucose counterregulation in insulin dependent diabetes mellitus: interaction of anti-insulin antibodies and impaired glucagon and epinephrine secretion. Diabetes 32:134-141

5. Hepburn DA, Deary IJ, Frier BM, Patrick AW, Quinn JD, Fisher BM (1991) Symptoms of acute insulin induced hypoglycaemia in humans with and without IDDM. Diabetes Care 14:949-957

6. Clarke WL, Gonder-Frederick LA, Richards FE, Cryer PE (1991) Multifactorial origin of hypoglycemic symptom unawareness in IDDM. Association with defective glucose counterregulation and better glycemic control. Diabetes 40: 680-685

7. Hepburn DA, Patrick AW, Eadington DW, Ewing DJ, Frier BM (1990) Unawareness of hypoglycaemia in insulin treated diabetic patients: prevalence and relationship to autonomic neuropathy. Diabet Med 7:711-717

8. Gold AE, MacLeod KM, Frier BM (1995) Frequency of severe hypoglycaemia in patients with type 1 diabetes with impaired awareness of hypoglycaemia. Diabetes Care 17:697-703
9. Cryer PE (1999) Hypoglycemia is the limiting factor in the management of diabetes. Diabetes Metab Res Rev 15:42-46

10. Amiel SA, Sherwin RS, Simonson DC, Tamborlane WV (1988) Effect of intensive insulin therapy on glycaemia thresholds for counterregulatory hormone release. Diabetes 37:901-907

11. Amiel SA, Tamborlance WV, Simonson DC, Sherwin RS (1987) Defective glucose counterregulation after strict glycemic control of insulin dependent diabetes mellitus. N Engl J Med 316:1376-1383

12. Heller SR, Cryer PE (1991) Reduced neuroendocrine and symptomatic responses to subsequent hypoglycaemia in nondiabetic humans. Diabetes 40:223-226

13. Ovalle F, Fanelli CG, Paramore DS, Hershey T, Craft S, Cryer PE (1998) Brief twice-weekly episodes of hypoglycaemia reduce detection of clinical hypoglycaemia in type 1 diabetes mellitus. Diabetes 47:1472-1479

14. Cranston I, Lomas J, Maran A, MacDonald I, Amiel SA (1994) Restoration of hypoglycaemia unawareness in patients with long duration insulin dependent diabetes mellitus. Lancet 344 : 283-287

15. Fanelli C, Pampanelli S, Epifano L et al (1994) Long-term recovery from unawareness, deficient counterregulation and lack of cognitive dysfunction during hypoglycaemia, following institution of rational, intensive insulin therapy in IDDM. Diabetologia 37:1265-1267

16. Fanelli CG, Epifano L, Rambotti AM et al (1993) Meticulous prevention of hypoglycemia normalizes the glycemic thresholds and magnitude of most of neuroendocrine responses to, symptoms of, and cognitive function during hypoglycemia in intensively treated patients with short-term IDDM. Diabetes 42:1683-1689

17. Kumagai AK, Kang YS, Boado RJ, Partridge WM (1995) Upregulation of blood-brain barrier GLUT 1 glucose transporter protein and mRNA in experimental chronic hypoglycaemia. Diabetes 44:1399-1404

18. Simpson IA, Appel NM, Hokari M et al (1999) Blood-barrier glucose transporter; effects of hypo- and hyperglycaemia revisited. J Neurochem 72:238-247

19. Boyle PJ, Nagy RJ, O'Connor AM, Kempers SF, Yeo RA, Qualls C (1994) Adaptation in brain glucose uptake following recurrent hypoglycaemia. Proc Natl Acad Sci U S A 92:93529356

20. Boyle PJ, Kempers SF, O'Connor AM, Nagy RJ (1995) Brain glucose uptake and unawareness of hypoglycaemia in patients with insulin dependent diabetes mellitus. N Eng J Med 333: $1726-1731$

21. Widom B, Simonson DC (1990) Glycemic control and neuropsychologic function during hypoglycemia in patients with insulin-dependent diabetes mellitus. Ann Intern Med 112:904 912

22. Fanelli CG, Parqamore DS, Hershey T et al (1998) Impact of nocturnal hypoglycemia on hypoglycemic cognitive function in type 1 diabetes. Diabetes 47:1920-1927

23. Segel SA, Fanelli GF, Carmen SD et al (2001) Blood to brain glucose transport, cerebral glucose metabolism and cerebral blood flow are not increased after hypoglycaemia. Diabetes 50:1911-1917

24. Cranston I, Reed LJ, Marsden PK, Amiel SA (2001) Changes in regional brain 18-fluorodeoxyglucose uptake at hypoglycaemia in Type 1 diabetic men associated with hypoglycaemia unawareness and counterregulatory failure. Diabetes 50:2329 2336

25. Criego AB, Tkac I, Kumar A, Thomas W, Gruetter R, Seaquist ER (2005) Brain glucose concentrations in patients with type 1 diabetes and hypoglycemia unawareness. J Neurosci Res 79: 42-47

26. Phelps ME, Huang SC, Hoffman EJ, Selin C, Sokoloff L, Kuhl D (1979) Tomographic measurement of local cerebral glucose metabolic rate in humans with F-18-2-fluoro-deoxy-D-glucose: validation of method. Ann Neurol 6:371-388 
27. Gjedde A, Wienhard K, Heiss W-D et al (1985) Comparative regional analysis of 2-fluorodeoxyglucose and methylglucose uptake in brain of four stroke patients. With special reference to the regional estimation of the lumped constant. J Cereb Blood Flow Metab 5:163-178

28. Nakanishi H, Cruz NF, Adachi K, Sokoloff L, Dienal GA (1996) Influence of glucose supply and demand on determination of brain glucose content with labelled methylglucose. J Cerebr Blood Flow Metab 16:439-449

29. Feinendegen LE, Herzog H, Wieler H, Patton DD, Schmid A (1986) Glucose transport and utilization in the human brain: model using carbon 11 methylglucose and positron emission tomography. J Nucl Med 27:1867-1877

30. Kuwabara H, Brust P, Steinbach J, Bergmann R (1999) Bloodbrain transport and metabolic rate of glucose measured with [11C] $O$-methyl-D-glucose (OMG). J Nucl Med 40:293

31. Maran A, Lomas J, Archibald H, Macdonald IA, Gale E, Amiel SA (1993) Double blind clinical and laboratory study of hypoglycaemia with human and porcine insulin in diabetic patients reporting hypoglycaemia unawareness after transferring to human insulin. Br Med J 306:167-171

32. Amiel SA, Simonson DC, Tamborlane WV, DeFronzo RA, Sherwin RS (1987) The rate of glucose fall does not affect the counterregulatory hormone responses to hypoglycemia. Diabetes 36:518-522

33. Bjurling P, Reineck R, Westerberg G et al (1995) Synthia, a compact radiochemistry system for automated production of radiopharmaceuticals. In: Link JM, Ruth TJ (eds) Sixth workshop on targetry and target chemistry, Vancouver, BC, Canada, Aug 1995. TRIUMF, Vancouver, p 282

34. MacDonald IA, Lake DM (1985) An improved method for extracting catecholamines from body fluids. J Neurosci Methods 13:239-248

35. Gjedde A, Diemer NH (1983) Autoradiographic determination of regional brain glucose content. J Cereb Blood Flow Metab 3:303-310

36. Feinendegen LE, Herzog H, Thompson KH (2001) Cerebral glucose transport implies individualized glial cell function. J Cereb Blood Flow Metab 21:1160-1170

37. Sokoloff L, Reivich M, Kennedy C et al (1997) The [14C] deoxyglucose method for the measurement of local cerebral glucose utilization: theory, procedure, and normal values in the conscious and anesthetized albino rat. J Neurochem 28:897916

38. Muzic RF Jr, Cornelius S (2001) COMKAT: compartment model kinetic analysis tool. J Nucl Med 42:636-645

39. Gruetter R, Ugurbil K, Seaquist ER (1998) Steady-state cerebral glucose concentrations and transport in the human brain. J Neurochem 8:397-408
40. Friston KJ, Holmes AP, Worsley KJ, Poline J-B, Frith CD, Frackowiak RSJ (1995) Statistical parametric maps in functional imaging: a general linear approach. Hum Brain Mapp 2:189-210

41. Friston KJ, Holmes A, Poline J-B, Frith CD (1996) Detecting activations in PET and fMRI: levels of inference and power. Neuroimage 40:223-235

42. Fanelli CG, Dence CS, Markham J et al (1998) Blood to brain glucose transport and cerebral glucose metabolism are not reduced in poorly controlled type 1 diabetes. Diabetes 47: 1444 1450

43. Brooks DJ, Gibbs JS, Sharp P et al (1986) Regional cerebral glucose transport in insulin dependent diabetic patients studied using [11C]3-O-methyl-D-glucose and positron emission tomography. J Cereb Blood Flow Metab 6; 240-244

44. Lane RD, Reiman EM, Axelrod B, Yun LS, Holmes A, Schwartz GE (1998) Neural correlates of levels of emotional awareness. Evidence of an interaction between emotion and attention in the anterior cingulate cortex. J Cogn Neurosci 10:525-535

45. Critchley HD, Mathias CJ, Josephs O et al (2003) Human cingulate cortex and autonomic control: converging neuroimaging and clinical evidence. Brain 126:2139-2152

46. Dagogo-Jack S, Rattarasarn C, Cryer PE (1994) Reversal of hypoglycemia unawareness, but not defective glucose counterregulation, in IDDM. Diabetes 43:1426-1434

47. DeRosa MA, Cryer PE (2004) Hypoglycemia and the sympathoadrenal system: neurogenic symptoms are largely the result of sympathetic neural, rather than adrenomedullary, activation. Am J Physiol Endocrinol Metab 287:E32-E41

48. Teves D, Videen TO, Cryer PE, Powers WJ (2004) Activation of human medial prefrontal cortex during autonomic responses to hypoglycemia. Proc Natl Acad Sci U S A 101:6217-6221

49. Owen AM, Herrod NJ, Menon DK et al (1999) Redefining the functional organization of working memory processes within human lateral prefrontal cortex. Eur J Neurosci 11:567-574

50. Sommerfield AJ, Deary IJ, McAuley V, Frier BM (2003) Short term, delayed and working memory are impaired during hypoglycaemia in individuals with type 1 diabetes. Diabetes Care 26:390-396

51. Harrad RA, Cockram CS, Plumb AP, Stone S, Fenwick P, Sonksen PH (1985) The effect of hypoglycaemia on visual function: a clinical and electrophysiological study. Clin Sci (Lond) 69:673-679

52. Schmahmann JD, Sherman JC (1998) The cerebellar cognitive affective syndrome. Brain 121:561-579 